\title{
The Extent to which Jordan Opportunities 3 Meets the General Guidelines for English Language Teaching in Jordan
}

\author{
Jarrah Mohammad AL-Jarrah \\ Curriculum and Instruction \\ Southern Illinois University/ Carbondale, Illinois/ USA \\ jarrahaljarrah@siu.edu
}

Tamer Mohammad AL-Jarrah

School of computing

University Utara Malaysia, 06010 UUM Sintok, Kedah

Tamer_uum_jarrah@yahoo.com

Rania Hassan Talafhah

Curriculum and Instruction

Southern Illinois University/ Carbondale, Illinois/ USA

rtalafhah@siu.edu

DOI: 10.5296/ijafr.v5i2.8014 URL: http://dx.doi.org/10.5296/ ijafr.v5i2.8014

\section{Introduction}

English has become the dominant foreign language in the non-English speaking world. Jordanian students learn English as a foreign language starting in the first grade and continue to do so until the twelfth grade.

Agrawal (2004) stated that evaluation plays a pivotal role in deciding what the learners learn and what the teachers teach in schools. The final objective of this evaluation is to detect the strengths and weaknesses of the textbooks with the purpose of improving them and to develop and improve the quality of the educational programs. 
Brown (1995) defined evaluation in a very general sense considering the curriculum as follows:

the systematic collection and analysis of all relevant information necessary to promote the improvement of the curriculum and to assess its effectiveness within the context of a particular instruction involved... (p.24

A good textbook should have some important qualities that meet learners' as well as teachers' needs. A textbook stands as a link between the English program and the teaching situation. It plays a vital role in teaching English as a second or foreign language from the primary stage through university English requirements. As in other fields, good textbooks are in heavy demand.

Kitao and Kitao (1997) stated that it is important for teachers to know how to choose the best material for instruction, how to make supplementary materials for the class, and how to adapt materials. He stated that the following qualities of good English textbooks:

1- English textbooks should have correct, natural, recent, and Standard English. Since students' vocabulary is limited, the vocabulary in textbooks should be controlled or the textbooks should provide information to help students understand vocabulary that they may not be familiar with. For lower-level students, grammar should also be controlled. Many textbooks use narratives and essays. It would be useful to have a variety of literary forms (for example, newspaper articles, poetry, or letters), so that students can learn to deal with different forms.

2- The cultural information included in English textbooks should be correct and recent. It should not be biased and should reflect background cultures of English. It should include visual aids etc., to help students understand cultural information.

3- Content English textbooks should be useful, meaningful and interesting for students. While no single subject will be of interest to all students, materials should be chosen based, in part, on what students, in general, are likely to find interesting and motivating.

4- Materials should be slightly higher in their level of difficulty than the students' current level of English proficiency. (Exceptions are usually made for extensive reading and extensive listening materials, which should be easy enough for students to process without much difficulty.) Materials at a slightly higher level of difficulty than the students' current level of English proficiency allow them to learn new grammatical structures and vocabulary.

5- English textbooks should have clear instructional procedure and methods, that is, the teacher and students should be able to understand what is expected in each lesson and for each activity. Though there are five elements in language instruction, and learners should be the center of instruction. However, materials often control the instruction, since teachers and learners tend to rely heavily on them. Materials that are appropriate for a particular class need to have an underlying instructional philosophy, approach, method and technique which suit the students and their needs. They should have correct, natural, current and Standard English. Teachers need to look for good materials, both commercial and non-commercial, all the time. They also need to be aware of commercialism and copyright issues concerning materials.

Litz (2006) stated ELT materials (textbooks) play a very important role in many language classrooms but in recent years there has been a lot of debate throughout the ELT profession 
on the actual role of materials in teaching English as a Second/Foreign Language (TESL/TEFL).

Griffiths (1995) stated that the following features of the materials as follow:

1-Material used should empower students and put them in control of their own learning.

2- Material should be presented in such a way that it is possible for the student to be self-monitoring.

3- Material should make it easy to divide the class into groups or pairs, to have conversations or role-play, and to allow the students to interact with each other.

4- Material suitable for an advanced student will be beyond the beginner's comprehension. Material suitable for a beginner will lack challenge for an advanced student. It is essential that material matches the abilities of the student.

5- Students usually react more favorably to bright, colorful, interesting, well-illustrated material.

6- Material must be sturdy, well-organized and well-indexed.

The textbook plays a vital role in teaching English as a second or foreign language from primary through tertiary education. Garinger (2002) maintains that a textbook can serve different purposes for teachers: a core resource, a source of supplemental material, an inspiration for classroom activities, even as the curriculum itself. Decisions related to textbook selection will affect teachers, students, and the overall classroom dynamic.

For a little over a decade, Jordan has witnessed a number of educational reforms meant to achieve sustainable educational outcomes to enable its students, and future work force, to better cope with the challenges of a competitive local, regional and global economy in which English is seen as a catalyst for success. English as a Foreign Language (EFL) has had the lion's share of these reforms for non-English major students in the Chinese higher education context. Initiatives to achieve better education outcomes for a sustainable future via more developed learning and assessment theories and technology are clearly articulated in its guideline document, the College English Curriculum Requirements (CECR) (CMoE, 2004; 2007). The stipulated College English assessment framework has taken two major moves.

Firstly, the original external examination system, the College English Test (CET) testing system is reformed in a substantial way; and secondly, formative assessment elements are advocated to incorporate into the summative assessment framework. Concern remains as to whether this reform of foreign origin could fit with the local context. The question is what issues need to be considered to avoid any potential pitfalls in practices? To what extent the implementation practices will be aligned with the policy rhetoric? And what the long term effect will be?

Prior to the adoption of Jordan Opportunities, which consists of three levels, in 2007, Advance through More Relevant Activities (AMRA) English textbook was used for eleventh and twelfth grades in Jordanian schools. According to Ababneh (2007), who was the first and only researcher to evaluate Jordan Opportunities 1, the main justification behind introducing Jordan Opportunities was to bridge the gap among Progress in English through Relevant Activities for Jordan (PETRA) previously taught to fifth through tenth grades, 
AMRA previously taught to eleventh and twelfth grades, and Action Pack taught to first through ninth grades. Currently, only Action Pack and Jordan Opportunities textbooks are in use throughout the basic and secondary stages in Jordanian public schools.

The adoption of the Jordan Opportunities series is part of a series of Jordanian educational reforms. Jordan Opportunities is a multi-level course that has been specially designed for Jordanian students learning English in grades10, 11 and 12 .The basic premise of the course is that secondary students learn English best when they are dealing with interesting and meaningful content. Thematic input provides a context for language and communication and provides a number of 'cognitive anchors' for learning English in a monolingual environment (Jordan Opportunities 3, cover page).

Jordan Opportunities 3 (Twelfth Grade) is a two-level course, organized into six topic-based modules. The first level course consists of Modules 1, 2 and 3. The second level covers Modules 4, 5 and 6. Within each module, there are several subtopics which explore the module theme in depth. For example, Module 1, entitled on wheels, covers the subtopics of cycling, traveling by airplane, solar car races and cars and traffic. The various components of Jordan Opportunities 3 were written by a number of authors. The Teacher's Book was authored by Mugglestone, Harris, Mower and Sikorzynska, the Student's Book was written by Harris, Mower and Anna Sikorzynska, while the Activity Book was exclusively written by Dean.

\section{Purpose and Question of this Pilot Study}

This study attempts to evaluate Jordan Opportunities 3 currently used for the twelfth grade in Jordanian public schools from supervisors' and teachers' perspectives. More specifically, it seeks to answer one question, namely, to what extant do Jordan Opportunities 3 adhere to the general guidelines for English language teaching in Jordan?

\section{Significance of the Study}

The Ministry of Education has been concerned with the improvement of the quality of basic education. Accordingly, a need arose to investigate English supervisors' and teachers' views about Jordan Opportunities 3 (Twelfth Grade) in order to improve it by stressing its strengths and avoiding points of weaknesses in future projects. To the researcher's best knowledge, it has not been evaluated yet. Aside from Ababneh (2007) who evaluated Jordan Opportunities for the tenth grade, the present study is the only one which examined Jordan Opportunities 3 (Twelfth Grade). This researcher hopes that this study may contribute to the development of teaching English language in Jordan and provide Jordanian English Language teachers, supervisors and the Ministry of Education with valuable information about these textbooks.

\section{Definition of Terms}

1- Jordan Opportunities : is a new multi-level course for teenagers .modules of topic-based units provide rich, contemporary content based on a wide variety of information themes. With a discovery approach to grammar and an upfront focus on vocabulary, Jordan Opportunities ensures the most effective language learning for students .

2- Evaluation: Brown (1995) defined evaluation in a very general sense considering the curriculum as follows: 


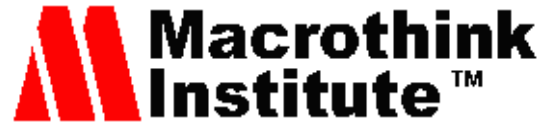

International Journal of Accounting and Financial Reporting ISSN 2162-3082 2015, Vol. 5, No. 2

....the systematic collection and analysis of all relevant information necessary to promote the improvement of the curriculum and to assess its effectiveness within the context of a particular instruction involved... (1995, p.24)

\section{Related Research}

To the best of these researchers' knowledge, no previous research was done on Jordan Opportunities 3, since the series has been adopted only recently. However, a sole study was conducted on Jordan Opportunities 1 in which Ababneh (2007) examined its content using a textbook analysis instrument, a questionnaire and an interview. He found that the language components and communications activities were not fairly balanced even though clear variation and focus on the national and the foreign culture aspects was evident. The philosophy underlying Jordan Opportunities was found relevant to the needs of the students and the Jordanian society. He further reported that the majority of the teachers were less interested in teaching listening and speaking than reading and writing.

Nevertheless, a good body of research was conducted to examine the pedagogical appropriateness of the other textbook series used in the different stages of the Jordanian school system (cf., among several others, -Barakat, Bataineh, Al-Karasneh, and Bataineh (2006) and Al-Omari (2002) of Action Pack; Al-Jarrah (1987), Al-Kofeiri (1997), El-Mostafa (1988), and Saleh (1990) of PETRA; Al-Momani (1998) of AMRA). These evaluations, which were essentially positive, were more concerned with the appropriateness of the content, layout, and language practice than the alignment, or lack thereof, of these textbooks with the guidelines for teaching English.

However, similar to the purpose of this research, Al-Shneiqat (2004, in Arabic) content analyzed first and second secondary stage English textbooks to identify the potential congruence of the values in them with the Jordanian philosophy of education. He found that the values in the textbooks have a $100 \%$ match to those in the Jordanian philosophy of education. He further reported that the most frequent values were maintaining the national culture, respecting national figure, scholars and writers, and appreciating the role of women.

\section{Sampling, Instrumentation, and Procedures}

The sample of this Pilot study consisted of a random sample of 5 supervisors and 20 twelfth grade teachers who use Jordan Opportunities textbook 3 (viz., Activity Book, Student's Book, and Teacher's Book) at the public of Irbid, Jerash, Ajloun, and Mafraq directorates of education in the second semester of the academic year 2014-2015.

To achieve the purpose of the study, the researcher developed and used a questionnaire to investigate the teachers' and supervisors' perceptions of Jordan Opportunities 3 (Twelfth Grade). The questionnaire will include the following domains: (1) content, 21 items; (2) layout, 13 items; (3) assessment, 6 items; (4) the Teacher's Book, 11 items; (5) the availability of English teaching/learning resources, 12 items;(6) language skills, 9 items; (7) stimulus/practice/revision, 8 items; (8) physical characteristics, 6 items; (9) appropriateness, 11 items; and (10) flexibility, 4 items.

The results of the pilot study shows a congruent between Jordan opportunities 3 (twelfth grade) and general guidelines for English language teaching in Jordan. The respondents' 
suggestions to improve Jordan Opportunities textbooks for the twelfth grade. They suggested that teachers be provided with a teacher's book, cassette, word list, phonetic description, DVD, laserdiscs, software, CD-ROM, dictionary, and visual aids; the number of units and grammar exercises be reduced; the number of periods per week be increased; repetition in the Activity Book be avoided; the book be modified to better reflect the Arab, Islamic and Jordanian culture, values, and Jordanian life style; the teachers be involved in writing the objectives; and Mini grammar and Grammar summary in the pages related to exercises be included in the Student's Book .

The General Guidelines and General and Specific Outcomes for the English Language Curriculum for the Basic and Secondary Stages helps the teacher with all aspects of course planning and instruction, gives instructions on how to present and deal with each task and helps teachers chart their students' progress. In addition, it introduces several guidelines which can contribute in teaching a good standard teaching.

The General Guidelines and General and Specific Outcomes for the English Language Curriculum for the Basic and Secondary Stages gives a detailed description of the knowledge and skills students are expected to acquire in grades 1-12 including accounts of how to develop four essential skills, use oral language accurately and effectively, develop an appreciation of and ability to respond to literature, help parents and students to understand the developmental nature of the English curriculum, and assist teachers in honing their teaching practice and ,thus, contribute to the development of both the learning and teaching of English in Jordan. The researcher discusses the main elements of the content of the teacher's book and their potential to help teachers in presenting the material of Jordan Opportunities for the twelfth grade.

Cunningsworth and Kuse (1991) claim that teachers' guides (TGs) are an important part of a textbook package, especially for teachers who are less experienced or whose command of English is not particularly strong. The availability and effectiveness of a TG can contribute greatly to achieving a good standard of teaching, through the provision of information about the language, guidance on teaching procedures, and a rationale for the course.

The Teacher's book of Jordan Opportunities includes three parts: one which deals with content of the module, one which deals with the key features of Jordan Opportunities, and a third which deals with teaching help, as discussed below:

\section{Module Content}

This part provides teachers with information about the sections of each module in both the Student's Book and Activity Book. It presents key words, grammar focus, warm-up, summary of grammar rules, skill focus, function file, strategies, comparing cultures, quote unquote, review pages, speaking and writing strategies, talkback, writing help, and progress check.

\section{Key Features}

This part provides teachers with detailed information about each element. It presents with topic-based modules, clear objectives and outcomes, process approach to skills, comprehensive skill development, and discovery approach to grammar, a three- dimensional approach to vocabulary, pronunciation, recycling, cultures, and learner development. 
Jordan Opportunities presents interesting and meaningful content; it gives secondary students opportunities to explore concerns and interests that are directly related to them. In Jordan Opportunities, directions for learning are clear. Modules, lessons and tasks have stages and lead up to clear communicative outcomes.

In Jordan Opportunities, Skills are integrated and staged systematically, so students can use the information or ideas from one skills activity while doing another. It introduces several activities to systematically develop the four skills. Its modules contain different reading texts which help students develop variety of reading strategies. It recycles and revises listening strategies that students have used at earlier levels of this course. It introduces different writing tasks and provides teachers with different strategies for teaching writing. Jordan opportunities introduces variety of speaking tasks which focus on communication i.e. fluency rather than accuracy.

Jordan Opportunities uses an inductive approach to learning grammar, in which students can discover grammar themselves and formulate rules of usage. It provides a comprehensive approach to vocabulary learning on three levels: firstly, it helps students to deal with lexical items in context; secondly, students have the chance to build up their own personal lexicon; thirdly, there are plenty of opportunities for students to actually use vocabulary in context.

Pronunciation is dealt with systematically in Jordan Opportunities 3, (Twelfth Grade), both at the level of individual sounds and at a suprasegmental level (dealing with features of extended speech). It builds on what students may have done in previous levels, modules, and lessons and extends their experience of the language. It introduces clear insights about English-speaking cultures and other cultures which help students understand other people and how to deal with them.

Students are encouraged to develop as independent and active learners of English. These skills and habits will make them better students throughout their educational lives. The following elements in the Student's Book and Activity Book help students become better learners. In Students' Book, there are module objective boxes, strategies boxes, writing help, and grammar summary and in Activity Book, there are grammar index and mini-grammar.

\section{Teaching help}

This part provides teachers with practical suggestions to help them use Jordan Opportunities for the twelfth grade. These suggestions are related to planning, classroom management, grammar, vocabulary, reading, writing, listening, speaking, and learner development.

In planning, Jordan Opportunities helps teachers use suggested routes through the material and adapt the content to their class by making a list of topic priorities. In classroom management, it helps teachers familiarize students with the key instructions and classroom language and gradually introduces group work.

In grammar, Jordan Opportunities encourages students to take their own grammar notes, work the grammar rules themselves; produces language tests and insures students' understanding of the grading system in the Activity Book. In vocabulary, Jordan Opportunities encourages students to select new words, focus on the strategies for learning vocabulary, and make time in class for vocabulary books. 
In reading, Jordan Opportunities encourages students to do pre-reading activities such as guessing and prediction, guess the meaning of words, discuss the texts and tasks with other students after they have done them, and read outside the class. In writing, Jordan Opportunities insures students' use of the writing help section to try out some written tasks in pairs/groups, to know the purpose and target audience of their writing and to edit/ revise for coherence and cohesion.

In listening, Jordan Opportunities prepares students before listening to raise their awareness of listening difficulties and focus on task achievement. In speaking, Jordan Opportunities allows preparation time, encourages individual practice, uses dictionaries to check pronunciation, rewards effort and participation, gives marks for oral performance, and gets students to make a list of words they find difficult to pronounce.

In learner development, Jordan Opportunities encourages students to keep diaries, use the objectives at the start of each module, and link self-assessment with their own assessment.

In summary, the teacher's book gives the teacher help with all aspects of course planning and teaching. It contains the objectives of each unit and lesson and gives instructions on how to present and expand each task. There are photocopiables sheets to help teachers chart their student's progress. It also contains detailed and flexible teaching notes for every unit and lesson. There are further activities, assessment guide, test guide, tapescripts, and answer keys. There are six tests on the six modules and their answer keys. After reading the Teacher's Book, the researcher found that it provides teachers with great help, not to mention that it introduces several guidelines which can contribute to quality teaching.

The researcher discusses congruent between Jordan Opportunities 3(Twelfth Grade) and general guidelines for English language teaching in Jordan. The Jordan Opportunities showed that content is based on accurate, current information. In addition, units are logically ordered. Layout also reflects the organization of the material, and the pictures are attractive to students. Assessment, language skills, appropriateness, English teaching/learning resources, and Teacher's Book are satisfactory for the Jordanian setting from the respondents' perspectives. Assessment tasks focus on language use in the classroom and focus on developing the students' linguistic abilities. In addition, the textbook presents a variety of assessment tools. The material is interesting and authentic. Also, the respondents view the writing help, grammar summary, assessment materials, work book, and answer key are useful for the students and easy for the teachers to use. In addition, the exercises and activities are varied and provided in the Activity Book adequate. Material requires a lot of preparation on the part of the teachers and the students.

The General Guidelines and General and Specific Outcomes for the English Language Curriculum for the Basic and Secondary Stages develop four essential skills including using oral language accurately and effectively and developing an appreciations of literature and the ability to respond to it and contribute to the development of both the learning and teaching of English in Jordan. It gives instructions how to present and deal with each task and contributes in teaching a good standard teaching. It also includes clear instructions and outcomes, guidance to methods of teaching and selecting teaching resources.

Jordan Opportunities 3 and the General Guidelines and General and Specific Outcomes for 


\section{Ml Macrothink \\ International Journal of Accounting and Financial Reporting

the English Language Curriculum for the Basic and Secondary Stages will:

1. Communicate information, ideas, opinions and feelings effectively for a variety of purposes in written, spoken and visual forms to interact and collaborate with others to accomplish goals;

2. Utilize critical thinking skills to make value judgment on texts, contexts and social norms in light of Arab-Islamic culture and values;

3. Read and understand both simplified and authentic texts (i.e., both original and real life) of a general nature and/or technical language and identify the main ideas from different ICT texts;

4. Apply the skills and strategies necessary for efficient utilization of electronic technology in lifelong learning contexts and in real life situations to gather, organize information and generate new words;

5. Translate texts from Arabic into English appropriately and vice verse;

6. Explore and respond creatively to Arabic and world literature as a way of knowing, developing personal values, understanding our cultural heritage and appreciating other cultures in light of the Arabic-Islamic culture;

7. Acquire a positive attitude towards English and realize its importance as a means for promoting mutual understanding amongst peoples and countries.

8. Teach all four skills (listening comprehension, speaking, reading, and writing).

9. Integrate culture with the four skills ((listening comprehension, speaking, reading, and writing) through emphasize cultural similarities and note differences to a positive manner.

10. Utilize authentic language and material whenever possible.

11. Be connected with linguistic (grammatical) accuracy from the beginning of instruction. Errors may become fossilized if ignored. However, students should not be expected to give only correct utterances, particularly not during communicative activities (oral and written).

12. Design the objectives so that it specifies what the student will be able to do by the end of the period.

13. Select strategies, technique, and activities from various methods and approaches to meet the diverse of students.

14. Use deductive, inductive, and/or guided discovery approaches depending on students' needs and the complexity of the material.

15. Utilize meaningful contexts to introduce new vocabulary or structures whenever possible without obscuring the teaching point (rather than disjointed sentences or examples). 


\section{References}

Ababneh, J. (2007). Analyzing the Content of "Jordan Opportunities" Series for the Basic Stage Jordanian Students and Investigating Teachers' and Supervisors' Opinions. Unpublished Doctoral Thesis, Amman Arab University for Graduated Studies, Amman, Jordan.

Agrawal, Mamta (2004). Curricular Reform in Schools: The Importance of Evaluation. Journal of Curriculum Studies, 36(3), 361-379.

Al-Barakat, A., Bataineh, R., Al-Karasneh, S. \& Bataineh, R. (2006). Jordanian EFL Teachers' Perceptions of the Appropriateness of Action Pack Textbook. ITL-international Journal of Applied Linguistics, 15, 33-65.

Al-Jarrah, Z. (1987). Analysis and Evaluation of the New TEFL Textbooks (PETRA) for the Fifth and Sixth Elementary Classes in Jordan. Unpublished Master's Thesis, Yarmouk University, Irbid, Jordan.

Al-Kofeiri, Q. (1997). An Evaluation of the English Textbook (PETRA) For The Tenth Grade In Jordan From Teachers' Perspectives. Unpublished Master's Thesis, Yarmouk University, Irbid, Jordan.

Al-Momani, N. (1998). An Evaluation of EFL Textbooks (AMRA) for the First and Second Secondary Classes in Jordan: Students' Teachers' and Supervisors' Perspectives. Unpublished Master's Thesis, Yarmouk University, Irbid, Jordan.

Al-Omari, B. (2002). An Evaluation of Action Pack: Teachers' and Supervisors' perspectives. Unpublished Master's Thesis, Yarmouk University, Irbid, Jordan.

Brown, James (1995). The Elements of Language Curriculum; A systematic Approach to Program Development. Boston: Heinle and Heinle Publishers.

Dean, M. (2007). Jordan Opportunities, Twelfth Grade, Activity Book. London: Longman.

El-Mostafa, A. (1988). An Evaluation of the TEFL Textbook (PETRA) for the First Preparatory Class in Jordan. Unpublished. Master's Thesis, Yarmouk University, Irbid, Jordan.

Garinger, D. (2002). Textbooks selection for the ESL classroom: Retrieved 12 March 2008 from http://www.cal.org/resources/digest/0210garinger.html

Garinger, Dawn (2002). Textbooks selection for the ESL classroom: Retrieved 12/3/2008 from http://www.cal.org/resources/digest/0210garinger.html ...

Griffiths, Carol (1995). Evaluating Materials for Teaching English to Adult Speakers of other Languages, Forum Journal 33 (3), 50.

Harris, M., Mower, D. \& Sikorznska, A. (2007). Jordan Opportunities Twelfth Grade, Teacher's Book. London: Longman.

Harris, M., Mower, D. \& Sikorznska, A. (2007). Jordan Opportunities, Twelfth Grade, Student's Book. London: Longman.

Jordanian Ministry of Education (2006). General Guidelines and General and Specific Outcomes for the English Language Curriculum for the Basic and Secondary Stages. Amman, Jordan. 


\section{Macrothink}

International Journal of Accounting and Financial Reporting

ISSN 2162-3082 2015, Vol. 5, No. 2

Kitao, Kenji and Kitao, Kathleen (1997). Selecting and Developing Teaching/Learning Materials. The Internet TESL Journal IV (4) Retrieved 12/3/2008 from http://iteslj.org/.

Litz, David (2006). Textbook Evaluation and ELT Management: A South Korean Case Study. Retrieved 12/3/2008 from http://www.asian-efl-journal.com/Litz thesis.pdf

Mugglestone, P., Harris, M., Mower, D. \& Sikorzynska, A. (2007). Jordan Opportunities, Twelfth Grade, Teacher's Book. London: Longman.

Saleh, N. (1990). An Evaluation of the TEFL Textbook (PETRA) for the Second Preparatory Class in Jordan. Unpublished Master's Thesis, Yarmouk University, Irbid, Jordan.

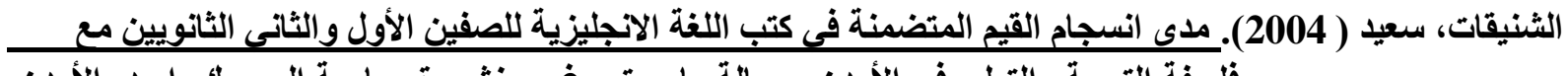

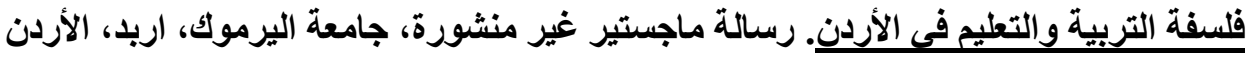

